\title{
Opioid Pain Medication Prescription for Chronic Pain in Primary Care Centers: The Roles of Pain Acceptance, Pain Intensity, Depressive Symptoms, Pain Catastrophizing, Sex, and Age
}

\author{
Carmen Ramírez-Maestre ${ }^{1, *} \mathbb{C}$, Ángela Reyes-Pérez ${ }^{1}$, Rosa Esteve ${ }^{1}{ }^{1}$, \\ Alicia E. López-Martínez ${ }^{1}{ }^{\mathbb{C}}$, Sonia Bernardes ${ }^{2}$ and Mark P. Jensen ${ }^{3}$ \\ 1 Instituto de Investigación Biomédica de Málaga, Facultad de Psicología, Andalucía Tech, \\ Universidad de Málaga, 29071 Málaga, Spain; angela_rp_@hotmail.com (Á.R.-P.); zarazaga@uma.es (R.E.); \\ aelm@uma.es (A.E.L.-M.) \\ 2 Instituto Universitario de Lisboa (ISCTE-IUL), Cis-IUL, Av. das Forças Armadas, 1649-026 Lisboa, Portugal; \\ sonia.bernardes@iscte-iul.pt \\ 3 Department of Rehabilitation Medicine, University of Washington, 325 9th Ave, Seattle, WA 98104, USA; \\ mjensen@uw.edu \\ * Correspondence: cramirez@uma.es; Tel.: +34-952-13-23-89
}

Received: 29 July 2020; Accepted: 1 September 2020; Published: 3 September 2020

check for updates

\begin{abstract}
Background: Psychological factors of patients may influence physicians' decisions on prescribing opioid analgesics. However, few studies have sought to identify these factors. The present study had a double objective: (1) To identify the individual factors that differentiate patients who had been prescribed opioids for the management of chronic back pain from those who had not been prescribed opioids and (2) to determine which factors make significant and independent contributions to the prediction of opioid prescribing. Methods: A total of 675 patients from four primary care centers were included in the sample. Variables included sex, age, pain intensity, depressive symptoms, pain catastrophizing, and pain acceptance. Results: Although no differences were found between men and women, participants with chronic noncancer pain who were prescribed opioids were older, reported higher levels of pain intensity and depressive symptoms, and reported lower levels of pain-acceptance. An independent association was found between pain intensity and depressive symptoms and opioid prescribing. Conclusions: The findings suggest that patient factors influence physicians' decisions on prescribing opioids. It may be useful for primary care physicians to be aware of the potential of these factors to bias their treatment decisions.
\end{abstract}

Keywords: opioid prescriptions; pain acceptance; pain catastrophizing; depression; sex; chronic pain

\section{Introduction}

Opioids have a selective affinity for central and peripheral opioid receptors and, via this mechanism, they can inhibit the transmission of nociceptive inputs and, therefore, the perception of pain [1]. Although opioids were originally formulated for acute and cancer pain, their use has expanded to treat a broad range of chronic pain conditions. However, recent research has highlighted the adverse effects of opioid medication due to the abuse of these drugs [2-5].

There is growing concern in Spain about the use and abuse of opioid analgesics [6,7]. In 2019, the Spanish Ministry of Healthcare published a report on medication use. The report analyzed the consumption of opioids based on prescription data provided by the Spanish National Health System. These data were obtained from private and public medical care centers, including hospitals. 
The results showed that the consumption of opioids in Spain had increased from 10.02 daily doses/1000 inhabitants/d in 2010 to 18.73 daily doses/1000 inhabitants/d in 2018.

This increase in opioid use has become a global phenomenon and is generating social concern. In a 2016 report, the International Narcotics Control Board (INCB) provided data on opioid abuse and its harmful effects. For example, a number of studies [8-10] have found that there is an increased mortality risk associated with long-term opioid therapy in individuals with chronic noncancer pain.

Although some physicians have previously suggested that opioids can benefit many patients [11,12], an increasing number of researchers have identified multiple adverse effects of long-term opioid use $[2,3,13]$. Their results are in line with the findings mentioned above. Moreover, new findings challenge the effectiveness of opioids in long-term chronic noncancer pain management $[14,15]$. Thus, despite growing evidence that opioids may be less than helpful for chronic pain management, the use of opioids for chronic pain management continues to increase [16].

Previous studies have shown that physicians' judgments of chronic pain patients are influenced by variables pertaining to the patient, physician, clinical condition, and clinical encounter $[17,18]$. Several studies have sought to identify the factors that differentiate individuals with chronic noncancer pain who have been prescribed opioids from those who have not been prescribed opioids [19-22]. Sex and age are two demographic variables that have been identified as such factors. For example, in a literature review, Serdarevic et al. [19] suggested that the likelihood of being prescribed opioids was higher in women than in men. Similarly, the American Geriatrics Society guideline panel [20] and Frenk et al. [21] suggested that the likelihood of being prescribed long-term opioids was higher in elderly women than in men or younger women. Recently, Bedene et al. [22] found that one of the risk factors associated with opioid prescription was being more than 65 years old.

In addition, an association has been found between a number of pain characteristics and the likelihood of being prescribed opioids. Several international guidelines have emphasized the relevance of assessing pain intensity when making decisions on prescribing opioids [2,23-27]. These guidelines may underlie the finding that higher levels of pain intensity were reported by individuals who were prescribed long-term opioid therapy than individuals who were not prescribed such therapy [28]. However, pain experts have questioned the safety and clinical utility of focusing on pain intensity as the only or primary factor to consider when making decisions on prescribing opioids [29-31].

An association has been found between a number of psychological variables and chronic opioid prescription. For example, Adams et al. [32] noted that depressive symptoms are common among patients who have been initiated [33] and maintained on long-term opioid treatment $[28,34,35]$. Other studies have found that higher levels of depression have been reported among patients who were prescribed opioids compared to those who have not been prescribed opioids [22,36,37].

Pain catastrophizing is a variable that is closely associated with depression [38-40]. Pain catastrophizing has been defined as exaggerated maladaptive cognitions in response to ongoing, anticipated, or recalled pain [41]. Research has shown that this factor has a central role in chronic pain [42-46]. Finnan et al. [47] found that opioid use was higher among patients who catastrophized about their pain, even if they reported low levels of pain. Similarly, Jensen et al. [36] showed that catastrophizing was more frequent among opioid users than non-opioid users.

Pain acceptance is another psychological factor that has been studied as a predictor of opioid prescription. Pain acceptance involves not trying to control or avoid pain. One key component of pain acceptance is having the goal of engaging in valued activities regardless of pain [48]. Recently, Rhodes et al. [49] studied the associations between the acceptance and committed action components of the psychological flexibility model [50] and pain severity, pain interference, and the risk of opioid misuse in chronic pain patients. They found an association between higher levels of pain severity and pain interference and a higher risk of opioid misuse and that these associations were mediated by both acceptance and committed action. Similarly, Clementi [51] found an association between lower levels of pain acceptance and increased inpatient hospitalizations and more opioid and nonopioid prescription medications, while controlling for pain intensity, age, and sex [51]. An association has also 
been found between lower pain acceptance and psychological dependence on pain medications in individuals with chronic pain in the general population [52] and decreased opioid use in an addiction treatment setting [53].

Thus, a number of factors have been shown to differentiate patients who have been prescribed opioids from those who have not been prescribed opioids. These factors include sex, age, pain intensity, depression, pain catastrophizing, and pain acceptance. However, patients cannot prescribe opioids for themselves. Receiving an opioid prescription requires clinical interaction with a health care provider. Very few studies have sought to identify the factors associated with physicians' decisions on prescribing opioid analgesics. Turk and Okifuji [37] studied the contribution of a set of factors that may influence the opioid prescribing practices of physicians for patients with chronic noncancer pain. The study was conducted in a tertiary care pain treatment center and included a sample of 191 individuals with heterogeneous pain disorders. The authors investigated the association between opioid prescribing by health care providers and a large set of patient variables, including sex, age, pain behavior, pain characteristics (i.e., pain severity, perceived life interference), the patient's sense of control over their lives, and the patient's levels of social support, pain disability, and depression. The results showed that patients prescribed opioids reported higher levels of depression and disability [37].

Sinnenberg et al. [54] conducted qualitative interviews with 52 emergency medicine physicians. These participants reported a range of factors in their decision-making, which included acuity, pain-related diagnosis, patient-reported pain severity, perceptions of the patient's trustworthiness, and health system issues (i.e., concerns about patient satisfaction scores, hospital policy, regulatory environment, and guidelines). In general, opioids were more likely to be prescribed to patients who were perceived to be honest than those perceived to be less honest. However, the authors did not ask the participants to describe how they determined this aspect [54].

Even less is known about opioid prescribing practices in the primary care setting [55]. In the only study we found on this topic, Tong et al. [56] found that long-term opioids were more likely to be prescribed to women than men and were more likely to be prescribed to patients who were more depressed than those who were less depressed. These results are in line with those on opioid use previously mentioned [19-21,37].

As Turk and Okifuji [37] recommended over 20 years ago, there remains a need for research on the factors associated with prescribing practices. Because most patients with chronic pain are treated by primary care physicians [57], knowledge regarding the factors associated with opioid prescribing in the primary care setting would be useful to identify the patients most likely to be prescribed opioids.

Given these considerations, the present study had a double objective: Firstly, to identify the individual factors that differentiate patients who had been prescribed opioids for the management of chronic back pain from those who had not been prescribed opioids and, secondly, to determine which factors make significant and independent contributions to the prediction of opioid prescribing when controlling for the other factors. No previous study has analyzed the effect of patients' levels of pain acceptance on doctors' decisions on prescribing opioids. Based on the findings from previous research, we hypothesized that the likelihood of being prescribed opioids would be higher in women and older patients than in men and younger patients. We also hypothesized that the likelihood of being prescribed opioids would be higher in patients who reported having higher levels of pain intensity, depressive symptoms, and pain catastrophizing and lower levels of pain acceptance than it would be in patients with lower levels of pain intensity, depressive symptoms, and pain catastrophizing and higher levels of pain acceptance. Given that these factors have not been analyzed within the same study as predictors of opioid prescription, we did not have any a priori hypotheses regarding which of these factors would make independent contributions to the prediction of opioid prescription. 


\section{Materials and Methods}

\subsection{Participants}

The participants of this study had also been participating in an ongoing larger study designed to investigate the role of pain fear avoidance and pain acceptance in chronic pain adjustment (Project name: "Psychological variables involved in pain chronification" PSI2008-01803/PSIC; HUM-566, P07-SEJ-3067). The project was conducted in accordance with the Declaration of Helsinki and received ethical clearance by the Institutional Ethics Review Board (ERC UMA) and the Regional Hospital Ethics Committee. To date, two articles that have used data from this study have been published $[44,58]$. However, neither of these articles had the same objectives as the present study. The recruitment process lasted from May 2008 to January 2012. Individuals were considered eligible for inclusion if, at the moment of their participation in the study, they were experiencing back pain and had been experiencing pain for at least the last 3 months; they were not being treated for a malignancy, terminal illness, or psychiatric disorder; and they were able to understand the Spanish language. The physicians who participated in the study reviewed the patients' clinical history. If the patients met the inclusion criteria, they were approached and invited to participate after completing the informed consent form. In total, 809 patients with back pain were invited to participate and 95 refused. The reasons for not participating were as follows: 15 patients did not reply to the phone calls; 63 stated they "had no time" for the assessment session; and 17 expressly refused participation. Of the patients initially contacted, 28 were excluded from the study because they did not meet the inclusion criteria or one of the exclusion criteria was present. Finally, 11 participants were also excluded because they gave us incomplete information. Thus, the final sample included 675 participants (see Figure 1). According to Austin and Steyerberg [59], a minimum subject-to-variable ratio of 5-to-1 in regression can produce stable and reasonably accurate estimates of the regression coefficients. Therefore, the sample size was excellent.

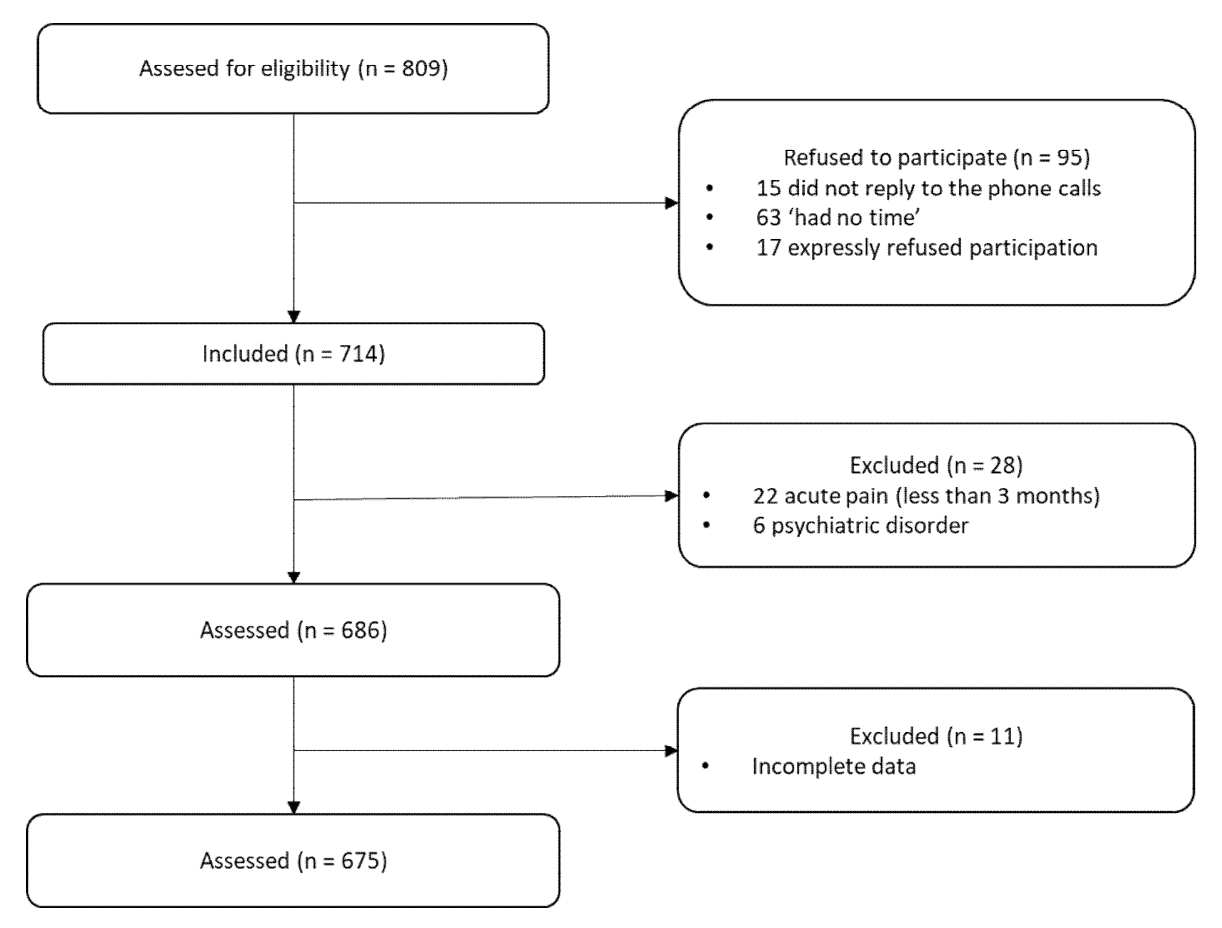

Figure 1. Flow chart of inclusion. 


\subsection{Variables and Instruments}

\subsubsection{Demographic and Clinical Variables}

Each participant was given a semi-structured interview with a psychologist to collect demographic, social, and medical history information.

\subsubsection{Pain Intensity}

Patients were asked to rate their least, average, and worst pain during the past 2 weeks, as well as their current pain on a scale ranging from 0 to 10, with 0 indicating "No pain" and 10 indicating "Pain as intense as you could imagine." A composite pain intensity score was calculated for each participant by calculating the average of these four ratings. Such composite scores have been shown to be very reliable measures of pain intensity in individuals with chronic pain [60]. In the present sample, internal consistency (Cronbach's alpha) for the composite pain score was 0.84 , indicating good reliability for this measure.

\subsubsection{Depressive Symptoms}

The depression subscale of the Spanish version of the Hospital Anxiety and Depression Scale was used to assess depressive symptoms. This is a self-reporting scale that contains two 7-item scales, one for anxiety and one for depression [61]. The internal consistency of the depression subscale has been shown to be high $(\alpha=0.86)$ in other samples [62]. In the present sample, internal consistency was 0.91 , indicating excellent reliability.

\subsubsection{Pain Catastrophizing}

A Spanish adaptation of the 13-item Pain Catastrophizing Scale (PCS) was used to assess pain catastrophizing [40,63]. Using this scale, respondents are asked to rate how often they experience catastrophizing thoughts and feelings when in pain [40]. The PCS can be used to assess three catastrophizing subdomains (rumination, magnification, and helplessness) that are strongly associated with one another. It also provides a total score. In the present study, all analyses used the total score. The Spanish Version of the complete PCS has been shown to have excellent internal consistency (Cronbach's alpha $=0.95)$ [64]. In the present sample, internal consistency was 0.97 , indicating excellent reliability.

\subsubsection{Pain Acceptance}

We used the Spanish version of the 20-item Chronic Pain Acceptance Questionnaire (CPAQ-SV) [65,66] to assess pain acceptance. The CPAQ-SV yields a total score and two subscale scores, assessing Pain Willingness and Activity Engagement. The subscales of the CPAQ-SV have been shown to have adequate to good internal consistency (Activity Engagement, $\alpha=0.85$; Pain Willingness, $\alpha=0.75$ ) and good criterion validity [65]. In the present study, we used the total score as the measure of pain acceptance. In the present sample, internal consistency was $\alpha=0.76$, indicating adequate reliability.

\subsection{Statistical Analysis}

Descriptive statistics were computed for the sample and study variables. Continuous variables are expressed as the mean and standard deviations and categorical variables are expressed as numbers and rates. The chi-square test-for the categorical predictors-and t-tests-for the continuous predictors-were used to assess the hypothesized associations between the criterion variable of the study (i.e., whether or not the patient was prescribed opioids) and patient sex, age, patient-reported pain intensity, severity of depressive symptoms, pain catastrophizing, and acceptance. Cohen's $\delta$ was also computed to assess the effect sizes of the associations. Values of Cohen's $\delta$ between 0.20 and 0.50 indicate a small effect size, between 0.50 and 0.80 indicate a medium effect size, and more than 
0.80 indicates a large effect size [67]. We examined the distributions of the study variables for normality using the Kolmogorov-Smirnov test to ensure that they met the assumptions for the planned regression analyses. To determine which predictors were independently associated with being prescribed opioids, we conducted a logistic regression analysis using opioid prescription (yes/no) as the criterion variable. In this analysis, all of the predictors were entered in a single step. Variables with $p \geq 0.05$ were excluded from the equation. All data analyses were performed using the Statistical Package for the Social Sciences version 22.0 (SPSS; Chicago, IL, USA).

\section{Results}

\subsection{Frequency Data for the Demographic and Clinical Variables}

The participants had chronic back pain and had been attending four primary care centers. It was found that every participant had been given at least one prescription: 85 were prescribed opioids and 590 were prescribed nonopioid analgesics. Participants could indicate more than one site of back pain. Table 1 shows the participants' characteristics.

Table 1. Frequency data for the demographic and clinical variables $(N=675)$.

\begin{tabular}{|c|c|c|c|}
\hline Variables & Mean & SD & Min/Max \\
\hline Age (years) & 45.4 & 12.9 & $16 / 79$ \\
\hline Time in pain (months) & 49 & 59.3 & $4 / 240$ \\
\hline \multirow[t]{2}{*}{ Pain intensity } & 5.3 & 1.6 & $0.5 / 9.5$ \\
\hline & $N$ & $\%$ & \\
\hline \multicolumn{4}{|l|}{ Sex } \\
\hline Men & 274 & 41 & \\
\hline Women & 401 & 59 & \\
\hline \multicolumn{4}{|l|}{ Marital status } \\
\hline Single & 125 & 18.5 & \\
\hline Married & 407 & 60.3 & \\
\hline Unmarried couple & 54 & 8.0 & \\
\hline Divorced & 39 & 5.8 & \\
\hline Separated & 24 & 3.6 & \\
\hline Widowed & 26 & 3.9 & \\
\hline \multicolumn{4}{|l|}{ Education } \\
\hline Reading and writing & 70 & 10.4 & \\
\hline Primary school & 231 & 34.2 & \\
\hline High school & 239 & 35.3 & \\
\hline University education & 135 & 20.1 & \\
\hline \multicolumn{4}{|l|}{ Work status } \\
\hline Housekeeping & 112 & 16.6 & \\
\hline Working & 352 & 52.2 & \\
\hline Studying & 17 & 2.5 & \\
\hline Unemployed & 102 & 15.1 & \\
\hline Retired & 92 & 13.6 & \\
\hline \multicolumn{4}{|l|}{ Site of pain } \\
\hline Upper back & 435 & 64.4 & \\
\hline Sacrum & 431 & 63.9 & \\
\hline Neck & 361 & 53.5 & \\
\hline Lower back & 251 & 37.2 & \\
\hline
\end{tabular}

\subsection{Univariate Differences between Individuals Given and Not Given an Opioid Prescription}

No statistically significant association was found between sex and opioid prescription (chi-square, $p=0.194)$. 
Table 2 shows the results of the $t$-tests comparing differences between the two groups of participants. These results are shown by age, pain intensity, depressive symptoms, pain acceptance, and pain catastrophizing. As shown, significant effects were found for age (small effect), pain intensity (medium effect), depressive symptoms, and pain acceptance (small effects). However, no significant association was found between the two groups in pain catastrophizing.

Table 2. Differences between participants who were prescribed and not prescribed opioids.

\begin{tabular}{|c|c|c|c|c|c|c|}
\hline & \multirow{2}{*}{$\begin{array}{c}\text { Participants } \\
\text { Prescribed Opioids } \\
(N=85)\end{array}$} & \multicolumn{2}{|c|}{$\begin{array}{c}\text { Participants not Prescribed } \\
\text { Opioids } \\
(N=590)\end{array}$} & \multicolumn{2}{|c|}{$p$ Value } & \multirow[t]{2}{*}{ Cohen's $\delta$} \\
\hline & & SD & Mean & SD & & \\
\hline Age & 49.04 & 11.05 & 44.88 & 13.12 & 0.002 & 0.34 \\
\hline Pain intensity & 6.03 & 1.49 & 5.14 & 1.61 & $<0.001$ & 0.57 \\
\hline Depressive symptoms & 17.35 & 5.49 & 14.67 & 5.51 & $<0.001$ & 0.49 \\
\hline Pain acceptance & 65.49 & 7.97 & 69.60 & 9.96 & $<0.001$ & 0.45 \\
\hline Pain catastrophizing & 23.87 & 10.82 & 23.34 & 8.85 & 0.669 & \\
\hline
\end{tabular}

\subsection{Multivariate Associations between the Study Predictors and Differences in Opioid Prescribing}

Pain catastrophizing was not included in the planned multivariate logistic regression analyses because no significant univariate association was found between this variable and differences in opioid prescribing (see Table 3). The logistic regression model was statistically significant $\left(\chi^{2}=37.0101\right.$, $p<0.001$ ) and explained $10 \%$ (Nagelkerke $R^{2}$ ) of the variance in the criterion variable. The model correctly classified $87.3 \%$ of the cases. Pain intensity and depressive symptoms contributed significant unique variance to the prediction of the criterion variable.

Table 3. Results of logistic regression analysis of variables associated with opioid prescribing.

\begin{tabular}{ccccc}
\hline & Beta & Wald & Exp(B) & $p$ \\
\hline Age & 0.017 & 2.729 & 1.017 & 0.099 \\
Pain intensity & 0.245 & 9.206 & 1.278 & 0.002 \\
Depressive symptoms & 0.061 & 6.318 & 1.063 & 0.012 \\
Pain acceptance & -0.013 & 1.027 & 0.987 & 0.311 \\
\hline
\end{tabular}

Note: No prescription for opioids was coded as 0 and a prescription for opioids was coded as 1 .

\section{Discussion}

The first objective of this study was to identify the individual factors that differentiate patients who had been prescribed opioids from those who had not been prescribed opioids in primary care settings. We identified four patient variables (age, pain intensity, severity of depressive symptoms, and pain acceptance) that had a significant univariate association with opioid prescribing. Pain intensity and the severity of depressive symptoms were independently associated with being prescribed opioids. The findings are relevant to understanding why certain patients are prescribed opioids and to educating primary care providers on aspects that should be taken into consideration when making decisions on prescribing opioids rather than other treatments, such as antidepressants or multidisciplinary pain management.

Evidence suggests that men and women experience chronic pain in different ways [68]. Compared to men, women tend to report pain more frequently, refer to more bodily locations, describe longer pain duration [69], and report greater intensity [70]. Huhn et al. [66] found that self-reported pain ratings and scores on catastrophizing were higher in women with chronic pain who misused prescription opioids than those in men. Several studies have found similar differences between women and men in relation to catastrophizing [71-73]. Although deaths due to prescription opioid overdose are higher in men than in women [74], opioid-related overdoses have recently increased more in women than in 
men [75]. However, sex differences are not always found in this context. For example, Coloma et al. [76] analyzed prevalence in the use of and dependence on opioid drugs in a sample of Spanish individuals with chronic noncancer pain. The authors found no significant differences between men and women in the use (or abuse) of prescribed opioids. Overall, these findings suggest that there may be sex-based differences in prescribing opioids for chronic pain, although there is very little information on this aspect. Previous findings have suggested that the likelihood of prescription opioid use is higher in women than in men [18]. Furthermore, it has been found that the likelihood of being prescribed opioids was higher in women than in men [77]. However, our results are not consistent with these findings. The reasons for the inconsistent findings are not entirely clear. In general, inconsistent findings in the research suggest that contextual factors may have influenced the effect of a predictor on a criterion variable. This possibility has been supported by recent reviews, suggesting that gender-related biases in pain treatment are due to the characteristics of the patients as well as those of the health care providers [71,78]. Thus, opioid prescribing may depend on the sex of the patient-or their age (see below) - as well as on the sex of the health care provider (or their age, experience, training, etc). Overall, the inconsistent findings in the literature suggest the need for further research to identify the potential moderators of the role of the patient in relation to opioid prescribing.

Several studies have addressed age-related predictors of opioid abuse. Some have suggested that age does not play a role $[79,80]$, whereas others have found that age is a risk factor in opioid prescription, with opioids being prescribed more often to older people than to younger patients [22,81]. Our findings suggest that, although patient age predicts opioid prescribing with a weak effect size, when it is analyzed as a univariate predictor, it is not significantly associated with opioid prescribing when other variables are controlled. This finding may help to explain the inconsistent findings reported in previous studies. Thus, when effects are weak, the statistical significance of a specific finding may depend on a variety of factors, such as the power (e.g., sample size) of the study, as well as the number of contextual factors related to the study population and setting. Overall, the findings suggest that age may play a role in physicians' decisions to prescribe opioids and that they should therefore consider the potential influence of age-related biases in their decisions, particularly when factors other than patient age should be playing a more relevant role in these decisions. Given the inconsistent findings in the literature, which suggest the existence of moderating factors, research is needed to help elucidate the factors that could interact with patient age in order to determine which of these factors have a relevant role in opioid prescribing.

Our findings on patient-reported pain intensity as a predictor of opioid prescribing are consistent with those of previous researchers [28]. They are also consistent with older international guidelines that have recommended taking the patient's reported pain intensity into account when making decisions about opioid prescribing $[23,24,26]$. However, these recommendations may now be outdated (see below). Pain intensity is a complex variable influenced by a larger number of biological, psychological, and social factors and is often assessed using rating scales [82]. The goal of analgesic treatment is to improve the patient's ability to achieve functional goals [32], and thus physicians should not decide to prescribe opioids based solely on the results of pain intensity ratings [83]. Moreover, recent observational studies have found that long-term opioid therapy is associated with poor pain outcomes and greater functional impairment $[84,85]$. Contemporary guidelines state that opioids should be used only when the improvements in pain and function outweigh the expected risks [86]. Therefore, variables other than pain intensity alone should be taken into account when making decisions on prescribing opioids.

We also found an association between the severity of depressive symptoms and opioid prescriptions in our sample. Chronic pain and depression are closely related [87]. Depressive symptoms in chronic pain populations have an estimated prevalence between 30\% and 50\% [88-91]. These percentages are much higher than those in the general population [92,93]. Depression can worsen chronic pain, which may encourage opioid prescribing [87]. Moreover, experimental and prospective clinical studies have shown that opioids provide less pain relief in patients with chronic low back pain and depressive 
symptoms than they do in nondepressed individuals [94,95]. In line with the results of the present study, previous research has found that negative affect is a risk factor for opioid prescription misuse and abuse $[96,97]$ and that individuals with chronic pain and comorbid depression are more likely to be prescribed opioids [22,98,99], prescribed higher doses of opioids [100], and prescribed opioids for longer periods [34]. These findings suggest that health care providers may inadvertently be prescribing opioids to treat depression, which in fact may make depression worse [90]. Sullivan suggested [87] that primary care physicians should be assessing depression in their patients before prescribing opioids. The Centers for Disease Control and Prevention Guideline for Prescribing Opioids for Chronic Pain (2016) recommended that physicians should ensure that treatment for depression is optimized and should consult with behavioral health specialists because treatment for depression can improve pain symptoms as well as depression. Therefore, the findings suggest that clinical practice may not be in line with current guidelines and that clinician knowledge concerning this issue should be updated as a matter of urgency. Indeed, if the objective of opioid treatment is to improve the patient's ability to achieve functional goals, it would be relevant to conduct a psychological evaluation of the patients, rather than simply relying on reported pain intensity, to ensure that opioid treatment is effective in improving quality of life.

Previous studies have highlighted the relevance of pain acceptance in the adjustment of individuals to chronic pain $[44,101]$. Other studies have found an association between lower levels of pain acceptance and high medical utilization [51] and psychological dependence on pain medications [52]. However, we found no significant association between the participants' reported levels of pain acceptance and opioid prescribing by primary care physicians. If this finding is replicated in future studies, it would suggest that health care providers may not need to screen patients' levels of pain acceptance, which would typically be done to identify a factor that may bias their decision to prescribe opioids.

The detrimental role of catastrophizing in managing and coping with pain is well documented [42-46]. In a sample of patients with sickle cell disease, Finnan et al. [47] found an association between higher levels of pain catastrophizing and the increased use of short-acting opioids. Furthermore, Jensen et al. [36] found that catastrophizing was more often reported by opioid users than by nonopioid users. Given these findings, we expected to find differences in levels of pain catastrophizing between the participants who were prescribed opioids and those who were not. However, the findings did not support this hypothesis. This lack of significant associations may be due to there being something unusual about the study context or study sample. If so, catastrophizing may play a role in opioid prescribing in some settings but not in others. Alternatively, it may be the case that the level of catastrophizing plays a relevant role in opioid use (i.e., in patients who have a prescription), but does not necessarily play a role in the prescribing behavior of health care providers. Future research is needed to address these issues.

This study has a number of limitations that should be considered when interpreting the results. Firstly, the cross-sectional design of the study precludes the possibility of drawing causal conclusions regarding the associations found. Longitudinal methods would be useful to investigate the role of pain intensity and the severity of depressive symptoms in prospectively predicting the likelihood of chronic pain patients being prescribed opioids. Secondly, the study population was recruited from just four primary care centers and included individuals willing to participate in the larger ongoing survey study. Thus, they may or may not be representative of individuals with chronic pain in other settings. Additional research is needed to determine the extent to which the present findings can be replicated in other samples of individuals with chronic pain.

\section{Conclusions}

We found significant univariate associations between patient age, pain intensity, and depressive symptoms and opioid prescribing for individuals with chronic back pain attending primary care centers. In multivariate analyses, pain intensity and depression alone contributed significant unique variance to the prediction of opioid prescribing. However, physicians should not base their decision to 
prescribe opioids only on the patients' reported levels of pain severity. Moreover, given that lower levels of pain relief with opioids are reported by patients with chronic pain and co-morbid depression than by patients without depression, physicians should consider whether treatments other than opioid medication may be more appropriate for patients with depression. These findings highlight the relevance of screening for depression in patients presenting with chronic back pain.

Primary care physicians write a large percentage of all opioid prescriptions, but little is known about the characteristics of patients who receive them. The findings from the present study emphasize the relevance of understanding all the variables related to opioid prescribing in primary care centers, rather than simply relying on reported pain intensity. Knowledge regarding these variables would be useful for identifying individuals who are more likely to be prescribed opioids. This knowledge could then be used to develop training programs for physicians to help them identify the patients most likely to be prescribed opioids, even when these analgesics may not be appropriate.

Author Contributions: Research design: C.R.-M., R.E., A.E.L.-M., and M.P.J.; research: C.R.-M., Á.R.-P., R.E., and A.E.L.-M., data collection: C.R.-M., R.E., and A.E.L.-M.; data analysis and interpretation: C.R.-M., R.E., Á.R.-P., A.E.L.-M. and S.B.; co-authors: C.R.-M., Á.R.-P., R.E., A.E.L.-M., S.B., and M.P.J. All authors have read and agreed to the published version of the manuscript.

Funding: This study was supported by grants from the Spanish Ministry of Science and Innovation (PSI2008-01803/PSIC) and the Regional Government of Andalusia (HUM-566, P07-SEJ-3067).

Conflicts of Interest: The authors declare no conflict of interest.

\section{References}

1. Use of Opioids in the Management of Chronic Noncancer Pain. Available online: https://www.uptodate. com/contents/use-of-opioids-in-the-management-of-chronic-non-cancer-pain (accessed on 6 July 2020).

2. Chou, R.; Fanciullo, G.J.; Fine, P.G.; Adler, J.A.; Ballantyne, J.C.; Davies, P.; Donovan, M.I.; Fishbain, D.A.; Foley, K.M.; Fudin, J.; et al. Clinical Guidelines for the Use of Chronic Opioid Therapy in Chronic Noncancer Pain. J. Pain 2009, 10, 113-130. [CrossRef] [PubMed]

3. Højsted, J.; Sjøgren, P. Addiction to Opioids in Chronic Pain Patients: A Literature Review. Eur. J. Pain 2007, 11, 490-518. [CrossRef] [PubMed]

4. Kaye, A.D.; Jones, M.R.; Kaye, A.M.; Ripoll, J.G.; Jones, D.E.; Galan, V.; Beakley, B.D.; Calixto, F.; Bolden, J.L.; Urman, R.D.; et al. Prescription Opioid Abuse in Chronic Pain: An Updated Review of Opioid Abuse Predictors and Strategies to Curb Opioid Abuse (Part 2). Pain Physician 2017, 20, S111-S133. [PubMed]

5. Volkow, N.D.; McLellan, A.T. Opioid Abuse in Chronic Pain-Misconceptions and Mitigation Strategies. N. Engl. J. Med. 2016, 374, 1253-1263. [CrossRef]

6. Santana Pineda, M.; Jover López-Rodrigalvarez, R.; Rodríguez Sainz, P.; Gómez Cortes, M.; Rodríguez Huertas, F.; Morgado Muñoz, I. Uso y Abuso de Opioides en el Área Norte de La Provincia de Cádiz. Rev. Soc. Esp. Dolor 2016, 23, 127-134. [CrossRef]

7. Secades Villa, R.; García, E.R.; Barbero, J.V.; Fernández Hermida, J.R.; Seco, G.V.; Garcia, J.M.J. El Consume de Psicofármacos En Pacientes Que Acuden a Atención Primaria En El Principado de Asturias (España). Psicothema 2003, 15, 650-655.

8. Chenaf, C.; Kaboré, J.L.; Delorme, J.; Pereira, B.; Mulliez, A.; Zenut, M.; Delage, N.; Ardid, D.; Eschalier, A.; Authier, N. Prescription Opioid Analgesic Use in France: Trends and Impact on Morbidity-Mortality. Eur. J. Pain 2019, 23, 124-134. [CrossRef]

9. Ray, W.A.; Chung, C.P.; Murray, K.T.; Hall, K.; Stein, C.M. Prescription of Long-Acting Opioids and Mortality in Patients with Chronic Noncancer Pain Supplemental Content at Jama.Com Original Investigation. JAMA 2016, 315, 2415-2423. [CrossRef]

10. Zeng, C.; Dubreuil, M.; Larochelle, M.R.; Lu, N.; Wei, J.; Choi, H.K.; Lei, G.; Zhang, Y. Association of Tramadol with All-Cause Mortality among Patients with Osteoarthritis. JAMA 2019, 321, 969-982. [CrossRef]

11. Furlan, A.D.; Sandoval, J.A.; Mailis-Gagnon, A.; Tunks, E. Opioids for Chronic Noncancer Pain: A Meta-Analysis of Effectiveness and Side Effects. CMAJ 2006, 174, 1589-1594. [CrossRef]

12. Kalso, E.; Edwards, J.E.; Moore, R.A.; Mcquay, H.J. Opioids in Chronic Noncancer Pain: Systematic Review of Efficacy and Safety. Pain 2004, 112, 372-380. [CrossRef] [PubMed] 
13. Kim, S.C.; Solomon, D.H. Towards Defining the Safer Use of Opioids in Rheumatology. Nat. Rev. Rheumatol. 2020, 16, 71-72. [CrossRef] [PubMed]

14. Bialas, P.; Maier, C.; Klose, P.; Häuser, W. Efficacy and Harms of Long-term Opioid Therapy in Chronic Non-cancer Pain: Systematic Review and Meta-analysis of Open-label Extension Trials with a Study Duration $\geq 26$ Weeks. Eur. J. Pain 2020, 24, 265-278. [CrossRef] [PubMed]

15. Veiga, D.R.; Monteiro-Soares, M.; Mendonça, L.; Sampaio, R.; Castro-Lopes, J.M.; Azevedo, L.F. Effectiveness of Opioids for Chronic Noncancer Pain: A Two-Year Multicenter, Prospective Cohort Study with Propensity Score Matching. J. Pain 2019, 20, 706-715. [CrossRef]

16. U.S. Opioid Prescribing Rate Maps|Drug Overdose|CDC Injury Center. Available online: https://www.cdc. gov/drugoverdose/maps/rxrate-maps.html (accessed on 24 June 2020).

17. Tait, R.C.; Chibnall, J.T. Physician Judgments of Chronic Pain Patients. Soc. Sci. Med. 1997, 45, 1199-1205. [CrossRef]

18. Tait, R.C.; Chibnall, J.T.; Kalauokalani, D. Provider Judgments of Patients in Pain: Seeking Symptom Certainty. Pain Med. 2009, 10, 11-34. [CrossRef]

19. Serdarevic, M.; Striley, C.W.; Cottler, L.B. Sex Differences in Prescription Opioid Use. Curr. Opin. Psychiatry 2017, 30, 238-246. [CrossRef]

20. Ickowicz, E. Pharmacological Management of Persistent Pain in Older Persons. J. Am. Geriatr. Soc. 2009, 57, 1331-1346. [CrossRef]

21. Frenk, S.; Porter, K.; Paulozzi, L. Prescriptyion Opioid Analgesic Use among Adults: United States, 1999-2012; US Department of Health and Human Services, Centers for Disease Control and Prevention, National Center for Health Statistics: Washington, DC, USA, 2015.

22. Bedene, A.; Lijfering, W.M.; Niesters, M.; van Velzen, M.; Rosendaal, F.R.; Bouvy, M.L.; Dahan, A.; van Dorp, E.L.A. Opioid Prescription Patterns and Risk Factors Associated with Opioid Use in the Netherlands. JAMA Netw. Open 2019, 2, e1910223. [CrossRef]

23. Calvo-Falcón, R.; Torres-Morera, L.-M.; Calvo-Falcón, R.; Torres-Morera, L.-M. Tratamiento con Opioides en Dolor Crónico No Oncológico: Recomendaciones para una Prescripción Segura. Rev. Soc. Española Dolor 2017, 24, 313-323. [CrossRef]

24. Cheung, C.W.; Chan, T.C.; Chen, P.P.; Chu, M.C.; Chui, W.C.; Ho, P.T.; Lam, F.; Law, S.W.; Lee, J.L.; Wong, S.H.; et al. Opioid Therapy for Chronic Noncancer Pain: Guidelines for Hong Kong. Hong Kong Med. J. 2016, 22, 496-505. [CrossRef] [PubMed]

25. Fischer, B.; Nakamura, N.; Ialomiteanu, A.; Boak, A.; Rehm, J. Assessing the Prevalence of Nonmedical Prescription Opioid Use in the General Canadian Population: Methodological Issues and Questions. Can. J. Psychiatry 2010, 55, 606-609. [CrossRef] [PubMed]

26. Kim, E.D.; Lee, J.Y.; Son, J.S.; Byeon, G.J.; Yeo, J.S.; Kim, D.W.; Yoo, S.H.; Hong, J.H.; Park, H.J.; Opioids Research Group in the Korean Pain Society. Guidelines for Prescribing Opioids for Chronic Noncancer Pain in Korea. Korean J. Pain 2017, 30, 18-33. [CrossRef] [PubMed]

27. Manchikanti, L.; Abdi, S.; Atluri, S.; Balog, C.C.; Benyamin, R.; Boswell, M.V.; Brown, K.R.; Bruel, B.M.; Bryce, D.A.; Burks, P.A.; et al. American Society of Interventional Pain Physicians (ASIPP) Guidelines for Responsible Opioid Prescribing in Chronic Noncancer Pain: Part 2-Guidance. Pain Physician 2012, 15, S67-S116.

28. Morasco, B.J.; Yarborough, B.J.; Smith, N.X.; Dobscha, S.K.; Deyo, R.A.; Perrin, N.A.; Green, C.A. Higher Prescription Opioid Dose is Associated with Worse Patient-Reported Pain Outcomes and More Health Care Utilization. J. Pain 2017, 18, 437-445. [CrossRef]

29. Bačkonja, M.M.; Farrar, J.T. Are Pain Ratings Irrelevant? Pain Med. 2015, 16, 1247-1250. [CrossRef]

30. Morone, N.; Weiner, D. Pain as the Fifth Vital Sign: Exposing the Vital Need for Pain Education. Clin. Ther. 2013, 35, 1728-1732. [CrossRef]

31. Pasero, C.; Quinlan-Colwell, A.; Rae, D.; Broglio, K.; Drew, D. American Society for Pain Management Nursing Position Statement: Prescribing and Administering Opioid Doses Based Solely on Pain Intensity. Pain Manag. Nurs. 2016, 17, 170-180. [CrossRef]

32. Adams, M.H.; Dobscha, S.K.; Smith, N.X.; Yarborough, B.J.; Deyo, R.A.; Morasco, B.J. Prevalence and Correlates of Low Pain Interference among Patients with High Pain Intensity who are Prescribed Long-Term Opioid Therapy. J. Pain 2018, 19, 1074-1081. [CrossRef] 
33. Dobscha, S.K.; Morasco, B.J.; Duckart, J.P.; Macey, T.; Deyo, R.A. Correlates of Prescription Opioid Initiation and Long-Term Opioid Use in Veterans with Persistent Pain. Clin. J. Pain 2013, 29, 102. [CrossRef]

34. Braden, J.B.; Sullivan, M.D.; Ray, G.T.; Saunders, K.; Merrill, J.; Silverberg, M.J.; Rutter, C.M.; Weisner, C.; Banta-Green, M.C.J.; Campbell, C.; et al. Trends in Long-Term Opioid Therapy for Noncancer Pain among Persons with a History of Depression. Gen. Hosp. Psychiatr. 2009, 31, 564-570. [CrossRef] [PubMed]

35. Smith, S.M.; Paillard, F.; McKeown, A.; Burke, L.B.; Edwards, R.R.; Katz, N.P.; Papadopoulos, E.J.; Rappaport, B.A.; Slagle, A.; Strain, E.C.; et al. Instruments to Identify Prescription Medication Misuse, Abuse, and Related Events in Clinical Trials: An ACTTION Systematic Review. J. Pain 2015, 16, 389-411. [CrossRef] [PubMed]

36. Jensen, M.K.; Thomsen, A.B.; Højsted, J. 10-Year Follow-up of Chronic Non-Malignant Pain Patients: Opioid Use, Health Related Quality of Life and Health Care Utilization. Eur. J. Pain 2006, 10, 423-433. [CrossRef] [PubMed]

37. Turk, D.C.; Okifuji, A. What Factors Affect Physicians' Decisions to Prescribe Opioids for Chronic Noncancer Pain Patients? Clin. J. Pain 1997, 13, 330-336. [CrossRef] [PubMed]

38. Edwards, R.; Cahalan, C.; Mensing, G.; Smith, M.; Haythornthwaite, J. Pain, Catastrophizing, and Depression in the Rheumatic Diseases. Nat. Rev. Rheumatol. 2011, 7, 216-224. [CrossRef]

39. Sullivan, M.J.L.; Rodgers, W.M.; Kirsch, I. Catastrophizing, Depression and Expectancies for Pain and Emotional Distress. Pain 2001, 91, 147-154. [CrossRef]

40. Sullivan, M.J.L.; Bishop, S.R.; Pivik, J. The Pain Catastrophizing Scale: Development and Validation. Psychol. Assess. 1995, 7, 524-532. [CrossRef]

41. Kapoor, S.; Thorn, B.E.; Bandy, O.; Clements, K.L. Pain Referents Used to Respond to the Pain Catastrophizing Scale. Eur. J. Pain 2015, 19, 400-407. [CrossRef]

42. Martinez-Calderon, J.; Jensen, M.; Morales-Asencio, J.; Luque-Suárez, A. Pain Catastrophizing and Function in Individuals with Chronic Musculoskeletal Pain. Clin. J. Pain 2019, 35, 279-293. [CrossRef]

43. Kroska, E. A Meta-Analysis of Fear-Avoidance and Pain Intensity: The Paradox of Chronic Pain. Scand. J. Pain 2016, 13, 43-58. [CrossRef]

44. Ramírez-Maestre, C.; Esteve, R.; López-Martínez, A. Fear-Avoidance, Pain Acceptance and Adjustment to Chronic Pain: A Cross-Sectional Study on a Sample of 686 Patients with Chronic Spinal Pain. Ann. Behav. Med. 2014, 48, 402-410. [CrossRef] [PubMed]

45. Ramírez-Maestre, C.; Esteve, R.; Ruiz-Párraga, G.; Gómez-Pérez, L.; López-Martínez, A.E. The Key Role of Pain Catastrophizing in the Disability of Patients with Acute Back Pain. Int. J. Behav. Med. 2017, 24, 239-248. [CrossRef] [PubMed]

46. Mankovsky, T.; Lynch, M.E.; Clark, A.J.; Sawynok, J.; Sullivan, M.J. Pain Catastrophizing Predicts Poor Response to Topical Analgesics in Patients with Neuropathic Pain. Pain Res. Manag. 2012, 17, $10-14$. [CrossRef] [PubMed]

47. Finan, P.H.; Carroll, C.P.; Moscou-Jackson, G.; Martel, M.O.; Campbell, C.M.; Pressman, A.; Smyth, J.M.; Tremblay, J.M.; Lanzkron, S.M.; Haythornthwaite, J.A. Daily Opioid Use Fluctuates as a Function of Pain, Catastrophizing, and Affect in Patients with Sickle Cell Disease: An Electronic Daily Diary Analysis. J. Pain 2018, 19, 46-56. [CrossRef] [PubMed]

48. McCracken, L.M.; Eccleston, C. Coping or Acceptance: What to Do about Chronic Pain? Pain 2003, 105, 197-204. [CrossRef]

49. Rhodes, A.; Marks, D.; Block-Lerner, J.; Lomauro, T. Psychological Flexibility, Pain Characteristics and Risk of Opioid Misuse in Noncancerous Chronic Pain Patients. J. Clin. Psychol. Med. Settings 2020. [CrossRef]

50. Mccracken, L.M.; Morley, S. The Psychological Flexibility Model: A Basis for Integration and Progress in Psychological Approaches to Chronic Pain Management. J. Pain 2014, 15, 221-232. [CrossRef]

51. Clementi, M.A.; Kao, G.S.; Monico, E. Pain Acceptance as a Predictor of Medical Utilization and School Absenteeism in Adolescents with Chronic Pain. J. Pediatr. Psychol. 2018, 43, 294-302. [CrossRef]

52. Elander, J.; Duarte, J.; Maratos, F.A.; Gilbert, P. Predictors of Painkiller Dependence among People with Pain in the General Population. Pain Med. 2014, 15, 613-624. [CrossRef]

53. Lin, L.A.; Bohnert, A.S.B.; Price, A.M.; Jannausch, M.; Bonar, E.E.; Ilgen, M.A. Pain Acceptance and Opiate Use Disorders in Addiction Treatment Patients with Comorbid Pain. Drug Alcohol. Depend. 2015, 157, 136-142. [CrossRef] 
54. Sinnenberg, L.E.; Wanner, K.J.; Perrone, J.; Barg, F.K.; Rhodes, K.V.; Meisel, Z.F. What Factors Affect Physicians' Decisions to Prescribe Opioids in Emergency Departments? MDM Policy Pract. 2017, 2. [CrossRef] [PubMed]

55. Bernardes, S.F.; Costa, M.; Carvalho, H. The Role of Physician Sex on Chronic Low-Back Pain Assessment and Treatment Prescriptions. J. Pain 2013, 14, 931-940. [CrossRef] [PubMed]

56. Tong, S.T.; Hochheimer, C.J.; Brooks, E.M.; Sabo, R.T.; Jiang, V.; Day, T.; Rozman, J.S.; Kashiri, P.L.; Krist, A.H. Chronic Opioid Prescribing in Primary Care: Factors and Perspectives. Ann. Fam. Med. 2019, 17, 200-206. [CrossRef]

57. García Vicente, J.A.; Vedia Urgell, C.; Vallès Fernández, R.; Reina Rodríguez, D.; Rodoreda Noguerola, S.; Samper Bernal, D. Quasi-Experimental Study of an Intervention on the Pharmacological Management of Non-Oncological Chronic Pain in Primary Care. Aten. Primaria 2019, 52, 423-431. [CrossRef] [PubMed]

58. Esteve, R.; Ramírez-Maestre, C. Pain Fear Avoidance and Pain Acceptance: A Cross-Sectional Study Comparing their Influence on Adjustment to Chronic Pain across Three Samples of Patients. Ann. Behav. Med. 2013, 46, 169-180. [CrossRef]

59. Austin, P.C.; Steyerberg, E.W. The number of subjects per variable required in linear regression analyses. J. Clin. Epidemiol. 2015, 68, 627-636. [CrossRef]

60. Jensen, M.; Karoly, P. Self-Report Scales and Procedures for Assessing Pain in Adults. In Handbook of Pain Assessment; Turk, D., Melzack, R., Eds.; Guilford Press: New York, NY, USA, 2001; pp. 15-34.

61. Zigmond, A.; Snaith, R. The Hospital Anxiety and Depression Scale. Acta Psychiatr. Scand. 1983, 67, 361-370. [CrossRef]

62. Ouintana, J.M.; Padierna, A.; Esteban, C.; Arostegui, I.; Bilbao, A.; Ruiz, I. Evaluation of the Psychometric Characteristics of the Spanish Version of the Hospital Anxiety and Depression Scale. Acta Psychiatr. Scand. 2003, 107, 216-221. [CrossRef]

63. García-Campayo, J.; Rodero, B.; Del Hoyo, Y.L.; Luciano, J.; Alda, M.; Gili, M. Validation of a Spanish Language Version of the Pain Self-Perception Scale in Patients with Fibromyalgia. BMC Musculoskelet. Disord. 2010, 11, 255. [CrossRef]

64. Muñoz, M.; Esteve, R. Reports of Memory Functioning by Patients with Chronic Pain. Clin. J. Pain 2005, 21, 287-291.

65. Mccracken, L.M.; Vowles, K.E.; Eccleston, C. Acceptance of Chronic Pain: Component Analysis and a Revised Assessment Method. Pain 2004, 107, 159-166. [CrossRef] [PubMed]

66. Bendayan, R.; Esteve, R.; Blanca, M. Empirical Evidence of the Validity of the Spanish Version of the Chronic Pain Acceptance Questionnaire: The Differential Influence of Activity Engagement and Pain Willingness on Adjustment to Chronic Pain. Br. J. Health Psychol. 2012, 17, 314-326. [CrossRef] [PubMed]

67. Cohen, J. Statistical Power Analysis for the Behavioral Sciences, 2nd ed.; Lawrence Erlbaum Associates Inc.: Mahwah, NJ, USA, 1988; Volume 13.

68. Huhn, A.S.; Tompkins, D.A.; Campbell, C.M.; Dunn, K.E. Individuals with Chronic Pain who Misuse Prescription Opioids Report Sex-Based Differences in Pain and Opioid Withdrawal. Pain Med. 2019, 20, 1942-1947. [CrossRef] [PubMed]

69. Melchior, M.; Poisbeau, P.; Gaumond, I.; Marchand, S. Insights into the Mechanisms and the Emergence of Sex-Differences in Pain. Neuroscience 2016, 338, 63-80. [CrossRef]

70. Fillingim, R.B. Sex, Gender, and Pain. In Principles of Gender-Specific Medicine: Gender in the Genomic Era, 3rd ed.; Elsevier: London, UK, 2017; pp. 481-496. [CrossRef]

71. Edwards, R.R.; Haythornthwaite, J.A.; Sullivan, M.J.; Fillingim, R.B. Catastrophizing as a Mediator of Sex Differences in Pain: Differential Effects for Daily Pain versus Laboratory-Induced Pain. Pain 2004, 111, 335-341. [CrossRef]

72. Keefe, F.J.; Lefebvre, J.C.; Egert, J.R.; Affeck, G.; Sullivan, M.J.; Caldwell, D.S. The Relationship of Gender to Pain, Pain Behavior, and Disability in Osteoarthritis Patients: The Role of Catastrophizing. Pain 2000, 87, 325-334. [CrossRef]

73. Sullivan, M.J.L.; Tripp, D.A.; Santor, D. Gender Differences in Pain and Pain Behavior: The Role of Catastrophizing. Cognit. Ther. Res. 2000, 24, 121-134. [CrossRef]

74. Calcaterra, S.; Glanz, J.; Binswanger, I. National Trends in Pharmaceutical Opioid Related Overdose Deaths Compared to Other Substance Related Overdose Deaths: 1999-2009. Drug Alcohol Depend. 2013, 131, $263-270$. [CrossRef] 
75. Unick, G.J.; Rosenblum, D.; Mars, S.; Ciccarone, D. Intertwined Epidemics: National Demographic Trends in Hospitalizations for Heroin- and Opioid-Related Overdoses, 1993-2009. PLoS ONE 2013, 8. [CrossRef]

76. Coloma-Carmona, A.; Carballo, J.L.; Rodríguez-Marín, J.; Pérez-Carbonell, A. Uso y Dependencia de Fármacos Opioides En Población Española Con Dolor Crónico: Prevalencia y Diferencias de Género. Rev. Clin. Esp. 2017, 217, 315-319. [CrossRef]

77. Simoni-Wastila, L. The Use of Abusable Prescription Drugs: The Role of Gender. J. Women's Health Gender Based Med. 2000, 9, 289-297. [CrossRef] [PubMed]

78. Samulowitz, A.; Gremyr, I.; Eriksson, E.; Hensing, G. "Brave men" and "emotional women": A theory-guided literature review on gender bias in health care and gendered norms towards patients with chronic pain. Pain Res. Manag. 2018, 2018, 6358624. [CrossRef] [PubMed]

79. Shah, A.S.; Blackwell, R.H.; Kuo, P.C.; Gupta, G.N. Rates and Risk Factors for Opioid Dependence and Overdose after Urological Surgery. J. Urol. 2017, 198, 1130-1136. [CrossRef] [PubMed]

80. Webster, L.; Webster, R. Predicting Aberrant Behaviors in Opioid-Treated Patients: Preliminary Validation of the Opioid Risk Tool. Pain Med. 2005, 6, 432-442. [CrossRef]

81. Schieber, L.Z.; Guy, G.P.; Seth, P.; Losby, J.L. Variation in Adult Outpatient Opioid Prescription Dispensing by Age and Sex-United States, 2008-2018. MMWR. Morb. Mortal. Wkly. Rep. 2020, 69, 298-302. [CrossRef]

82. McCaffery, M.; Herr, K.; Pasero, C. Assessment Tools. In Pain Assessment and Pharmacologic Management; Pasero, C., McCaffery, M., Eds.; Elsevier/Mosby.: St. Louis, MO, USA, 2011; pp. 33-176.

83. Krebs, E.E.; Gravely, A.; Nugent, S.; Jensen, A.C.; DeRonne, B.; Goldsmith, E.S.; Kroenke, K.; Bair, M.J.; Noorbaloochi, S. Effect of Opioid vs. Nonopioid Medications on Pain-Related Function in Patients with Chronic Back Pain or Hip or Knee Osteoarthritis Pain the SPACE Randomized Clinical Trial. JAMA 2018, 319, 872-882. [CrossRef]

84. Sjøgren, P.; Grønbæk, M.; Peuckmann, V.; Ekholm, O. A Population-Based Cohort Study on Chronic Pain: The Role of Opioids. Clin. J. Pain 2010, 26, 763-769. [CrossRef]

85. Turner, J.; Shortreed, S.; Saunders, K.; LeResche, L. Association of Levels of Opioid Use with Pain and Activity Interference among Patients Initiating Chronic Opioid Therapy: A Longitudinal Study. Pain 2016, 157, 849. [CrossRef]

86. Dowell, D.; Haegerich, T.M.; Chou, R. CDC Guideline for Prescribing Opioids for Chronic Pain-United States, 2016. JAMA 2016, 315, 1624-1645. [CrossRef]

87. Sullivan, M.D. Depression Effects on Long-Term Prescription Opioid Use, Abuse, and Addiction. Clin J. Pain 2018, 34, 878-884. [CrossRef]

88. Salazar, A.; Dueñas, M.; Mico, J.A.; Ojeda, B.; Agüera-Ortiz, L.; Cervilla, J.A.; Failde, I. Undiagnosed Mood Disorders and Sleep Disturbances in Primary Care Patients with Chronic Musculoskeletal Pain. Pain Med. 2013, 14, 1416-1425. [CrossRef] [PubMed]

89. Sullivan, M.J.L.; Adams, H.; Tripp, D.; Stanish, W.D. Stage of Chronicity and Treatment Response in Patients with Musculoskeletal Injuries and Concurrent Symptoms of Depression. Pain 2008, 135, 151-159. [CrossRef] [PubMed]

90. Bair, M.; Robinson, R.; Katon, W.; Kroenke, K. Depression and Pain Comorbidity. Arch. Intern. Med. 2003, 12, 34-43. [CrossRef] [PubMed]

91. Breivik, H.; Collett, B.; Ventafridda, V.; Cohen, R.; Gallacher, D. Survey of Chronic Pain in Europe: Prevalence, Impact on Daily Life, and Treatment. Eur. J. Pain 2006, 10, 287-333. [CrossRef] [PubMed]

92. Alonso, J.; Angermeyer, M.C.; Bernert, S.; Bruffaerts, R.; Brugha, T.S.; Bryson, H.; Girolamo, G.; Graaf, R.; Demyttenaere, K.; Gasquet, I.; et al. Use of Mental Health Services in Europe: Results from the European Study of the Epidemiology of Mental Disorders (ESEMeD) Project. Acta Psychiatr. Scand. 2004, 109, 47-54. [CrossRef]

93. Haro, J.M.; Palacín, C.; Vilagut, G.; Martínez, M.; Bernal, M.; Luque, I.; Codony, M.; Doltz, M.; Alonso, J. Grupo ESEMeD-España. Prevalencia de Los Trastornos Mentales y Factores Asociados: Resultados Del Estudio ESEMeD-España. Med. Clin. 2006, 126, 445-451. [CrossRef]

94. Wasan, A.D.; Michna, E.; Edwards, R.R.; Katz, J.N.; Nedeljkovic, S.S.; Dolman, A.J.; Janfaza, D.; Isaac, Z.; Jamison, R.N. Psychiatric Comorbidity is Associated Prospectively with Diminished Opioid Analgesia and Increased Opioid Misuse in Patients with Chronic Low Back Pain. J. Am. Soc. Anasthesiol. 2015, 123, 861-872. [CrossRef] 
95. Wasan, A.; Davar, G.; Jamison, R. The Association between Negative Affect and Opioid Analgesia in Patients with Discogenic Low Back Pain. Pain 2005, 117, 450-461. [CrossRef]

96. Feingold, D.; Brill, S.; Goor-Aryeh, I.; Delayahu, Y.; Lev-Ran, S. The Association between Severity of Depression and Prescription Opioid Misuse among Chronic Pain Patients with and without Anxiety: A Cross-Sectional Study. J. Affect. Disord. 2018, 235, 293-302. [CrossRef]

97. Gilam, G.; Sturgeon, J.; You, D.; Darnall, B.; Mackey, S. Negative Affect as a Predictor of Opioid Prescription Misuse and Abuse in Chronic Pain Patients: A Collaborative Health Outcomes Information Registry Study. J. Pain 2019, 20, S17. [CrossRef]

98. Davis, M.A.; Lin, L.A.; Liu, H.; Sites, B.D. Prescription Opioid Use among Adults with Mental Health Disorders in the United States. J. Am. Board Fam. Med. 2017, 30, 407-417. [CrossRef]

99. Seal, K.H.; Shi, Y.; Cohen, G.; Cohen, B.E.; Maguen, S.; Krebs, E.E.; Neylan, T.C. Association of Mental Health Disorders with Prescription Opioids and High-Risk Opioid Use in US Veterans of Iraq and Afghanistan. JAMA 2012, 307, 940-947. [CrossRef]

100. Merrill, J.O.; Von Korff, M.; Banta-Green, C.J.; Sullivan, M.D.; Saunders, K.W.; Campbell, C.I.; Weisner, C. Prescribed Opioid Difficulties, Depression and Opioid Dose among Chronic Opioid Therapy Patients. Gen. Hosp. Psychiatry 2012, 34, 581-587. [CrossRef]

101. McCracken, L.M.; Vowles, K.E. Acceptance of Chronic Pain. Curr. Pain Headache Rep. 2006, 10, 90-94. [CrossRef]

(C) 2020 by the authors. Licensee MDPI, Basel, Switzerland. This article is an open access article distributed under the terms and conditions of the Creative Commons Attribution (CC BY) license (http://creativecommons.org/licenses/by/4.0/). 